\section{Suicide in children and adolescents in England and Wales 1970-1998}

\author{
G. M. G. MCCLURE
}

This paper reviews the changes which have occurred in officially recorded suicide rates in England and Wales for young people between 10 and 19 years of age between 1970 and 1998. Changes in suicide in the whole population of England and Wales between 1960-1997 have been discussed in an earlier paper (McClure, 2000a). It is necessary to examine the younger age groups in more detail, because their characteristics are different and the pattern of suicide behaviour is dissimilar to that of the adult population (McClure, 1984b, 1994). In the 1980s and early 1990s there was concern about a substantial increase in rates of suicide in young males (McClure, $1984 b$, 1994), although there were signs of a reversal in this pattern in the mid1990s (Kelly \& Bunting, 1998). Despite this, rates of suicide in older male adolescents and young adults remain alarmingly high (Kelly \& Bunting, 1998).

Trends in suicide in Britain have been influenced by changes in the lethality and ease of availability of commonly used methods of suicide (Gunnell et al, 1999a; McClure, 2000a). The increase in deaths by overdose in teenagers during the 1960 s and 1970s and subsequent decrease during the 1980s has been reported previously (McClure, 1986). Similar patterns were evident, although at a much lower level, in younger adolescents, aged 10-14 years, up until the mid-1980s (McClure, 1988). Later, until the early 1990s a high proportion of young male adults committed suicide using carbon monoxide in car exhaust fumes (Kelly \& Bunting, 1998), but there is evidence that this method has started to become less frequent as the number of cars fitted with catalytic converters has increased (McClure, 2000a). There has been a recent increase in hanging in young people of both genders in England and Wales (Kelly \& Bunting, 1998; McClure, 2000a).

In this paper it has been considered necessary to examine 'undetermined' and 'accidental' deaths by methods comparable to suicide. This is because suicides may be misclassified where the coroner considers that there is insufficient evidence that the injury was self-inflicted and the individual intended to die (McClure, 1984a). Actual suicide rates in young people may be at much higher levels than the official suicide rate (McClure, 1994; Madge \& Harvey, 1999).

\section{METHOD}

Annual suicide statistics are available from the Office for National Statistics (19911998), the Office of Population Censuses and Surveys (1974-1990) and the Registrar General's Office (1970-1973). By using census-derived mid-year population estimates for five-year age bands, the rates for 10-14-year-olds and 15-19-year-olds are calculated. Changes in rates of suicide by different methods are also examined. A similar method is used to obtain rates for undetermined death and accidental death by categories comparable to suicide.

\section{RESULTS}

\section{Suicide, undetermined and} accidental death in 15-19-year-olds

Figure 1 demonstrates the rates of suicide for males and females aged 15-19 years in England and Wales between 1970 and 1998. The suicide rate for males aged 1519 years increased by $72 \%$ between 1970 and 1990, and remained at a relatively high rate throughout the 1990s (see Table 1). The suicide rate for females aged 15-19 years decreased slightly between the 1970 s and the 1980s, with low rates persisting into the 1990s.

The rate of undetermined deaths for 15-19-year-old males increased from 12 per million in 1970 to 49 per million in 1998. For females, there was a similar trend, with undetermined deaths increasing from five per million in 1970 to 20 per million in 1998. There has thus been an approximately four-fold increase in undetermined death rate for both males and females aged 15-19 years between 1970 and 1998.

The accidental death rate for methods similar to suicide in males decreased from 51 per million in 1970 to 34 per million in 1998. For females the accidental death rate decreased from 13 per million in 1970 to 10 per million in 1998 . The substantial rise in undetermined deaths is 


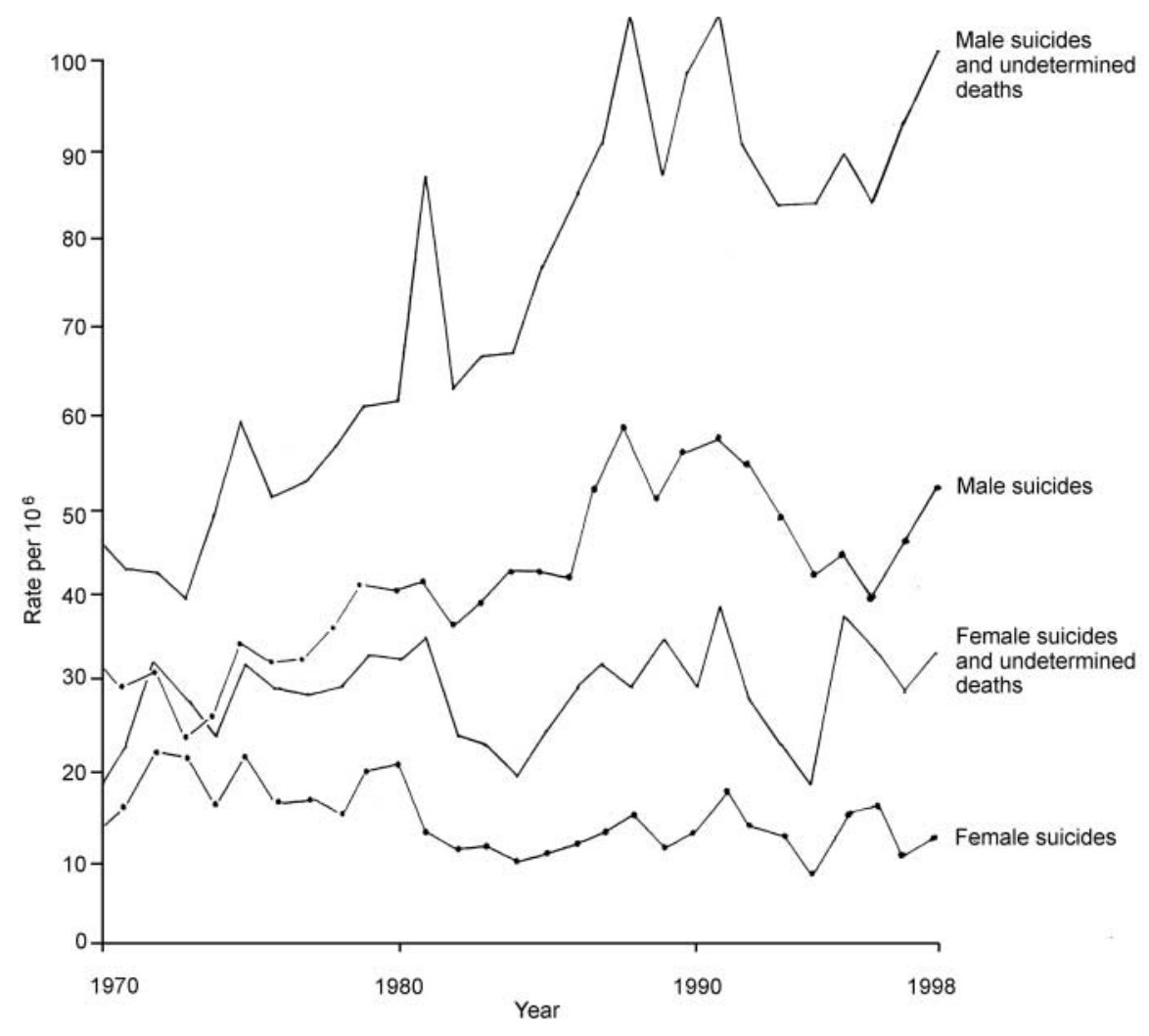

Fig. I Suicide and undetermined death in the 15-19-year-old age group in England and Wales. therefore partially, but not entirely, offset by this decrease in accidental deaths.

\section{Suicide by different methods in 15-19-year-olds}

Suicide by poisoning by solid or liquid substances (E950), including overdoses, increased up to 1980 and then decreased between 1980 and 1998, for both genders, as shown in Fig. 2. Whereas there were 47 suicides by this method in 1980 ( 25 males, 22 females) there were only 21 in 1998 (11 males, 10 females). Suicide by poisoning with gases other than domestic gas (E952) increased between 1970 and 1990, particularly in males. The majority of these deaths were by poisoning with vehicle exhaust gas (E952.0), as shown in Fig. 3. In 1970 there was only one male death by this method, increasing to 23 males and two females in 1990. This has decreased to three males

There has been a substantial increase in suicide by hanging, strangulation and suffocation (E953) in males, as shown in Fig. 4. Suicide by this method increased from 14 males and three females in 1970 to 54 males and 3 females in 1998. Sixty-three per cent of all male suicides in this age group were by hanging in 1998 . and one female in 1998.
There has been little change in suicide by other methods such as drowning (E954), with only two male deaths in 1998 , or suicide by cutting and piercing instruments (E956), with only one male death in 1998. Suicide by firearms (E955) is now also at very low levels, with only two male deaths by this method in 1998 . There were four male and two female deaths by jumping from a high place (E957) in 1998. Suicides by other and unspecified means (E950) totalled 10 males and five females in 1998. The majority of these deaths are by jumping or lying before moving vehicles.

\section{Suicide, undetermined and accidental death in 10-14-year-olds}

There have been no recorded suicides in children under 10 years between 1970 and 1998. As numbers are very small, suicides for children aged 10-14 years have been aggregated into decades (see Table 2). There was no change in rate for males aged 10-14 years between the 1970 s and the 1990s and the rate for females decreased very slightly. The actual numbers of recorded suicides for both genders remains extremely low.

The numbers for undetermined deaths are small for the 10-14 year age band and have, therefore, been aggregated into decades (see Table 2). For both genders, there has been an increase in undetermined death since the 1970s, although actual numbers

There were substantial changes in accidental deaths by causes similar to suicide for males, with a decrease from 27.7 per million in the 1970 s to 11.1 per million in the 1990s. For females, the rate decreased from 4.9 per million in the 1970 s to 3.4 in the 1990s. This decrease in accidental remain low.

Table I Suicide, undetermined death and accidental death by methods similar to suicide in I5-19-year-olds in England and Wales

\begin{tabular}{|c|c|c|c|c|c|c|c|c|}
\hline & \multicolumn{2}{|c|}{1970} & \multicolumn{2}{|c|}{1980} & \multicolumn{2}{|c|}{1990} & \multicolumn{2}{|c|}{1998} \\
\hline & $n$ & (Rate') & $n$ & (Rate') & $n$ & (Rate') & $n$ & (Rate') \\
\hline \multicolumn{9}{|l|}{ Suicide } \\
\hline Male & 55 & (33) & 84 & $(4 I)$ & 100 & (57) & 86 & (52) \\
\hline Female & 22 & (14) & 39 & (20) & 23 & (13) & 21 & (I3) \\
\hline \multicolumn{9}{|c|}{ Undetermined } \\
\hline Male & 21 & (12) & 45 & (22) & 74 & (42) & 81 & (49) \\
\hline Female & 8 & (5) & 22 & (II) & 26 & $(16)$ & 31 & (20) \\
\hline \multicolumn{9}{|l|}{ Accidental } \\
\hline Male & 87 & (5I) & 88 & (43) & 82 & $(47)$ & 56 & (34) \\
\hline Female & 21 & (13) & 21 & (II) & 16 & (10) & 17 & (10) \\
\hline \multicolumn{9}{|c|}{ Suicide and undetermined } \\
\hline Male & 76 & (45) & 129 & (63) & 174 & (99) & 167 & $(10 \mathrm{I})$ \\
\hline Female & 30 & (19) & 61 & (3I) & 49 & (29) & 52 & $(33)$ \\
\hline \multicolumn{9}{|c|}{ Suicide and undetermined and accidental } \\
\hline Male & 163 & (96) & 217 & (106) & 256 & $(146)$ & 223 & (135) \\
\hline Female & 51 & (32) & 82 & (42) & 65 & (39) & 69 & (43) \\
\hline
\end{tabular}

I. Rate per million population aged $15-19$ years. 


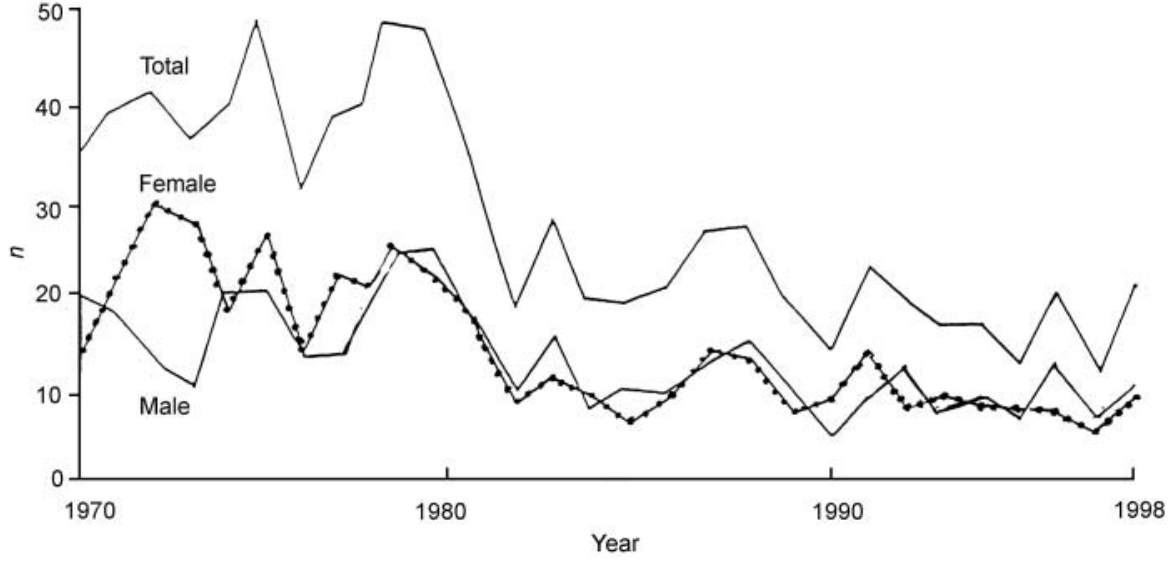

Fig. 2 Suicide by poisoning by solid or liquid substances, in the 15-19-year-old age group in England and Wales.

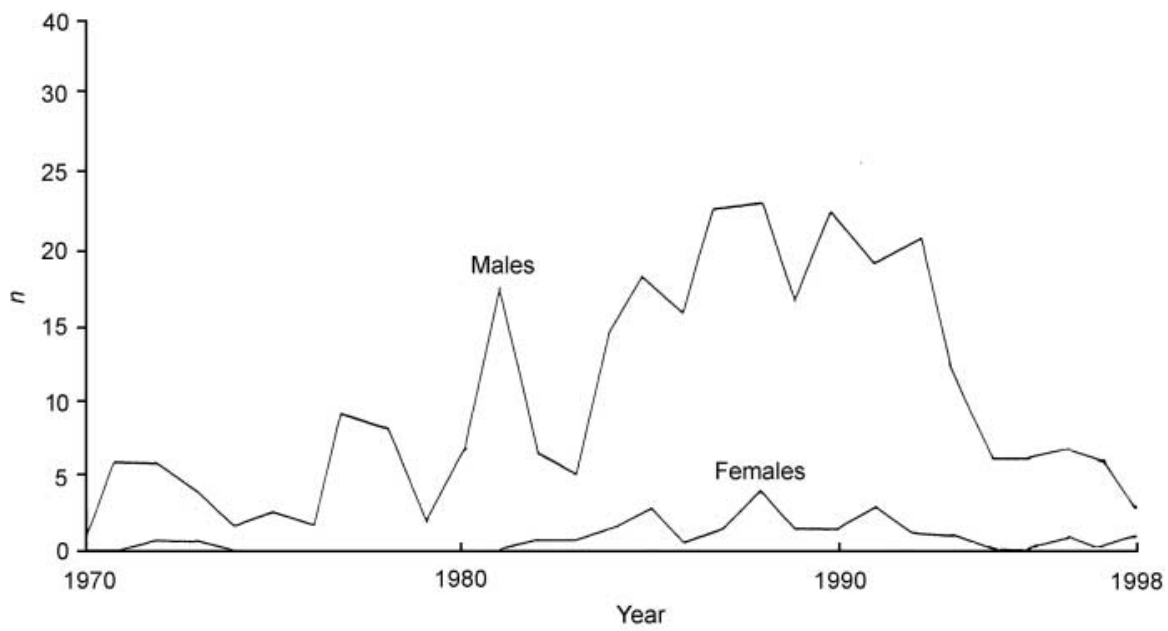

Fig. 3 Suicide by poisoning with motor vehicle exhaust gas (ICD E952.0) in the 15-19-year-old age group in England and Wales.

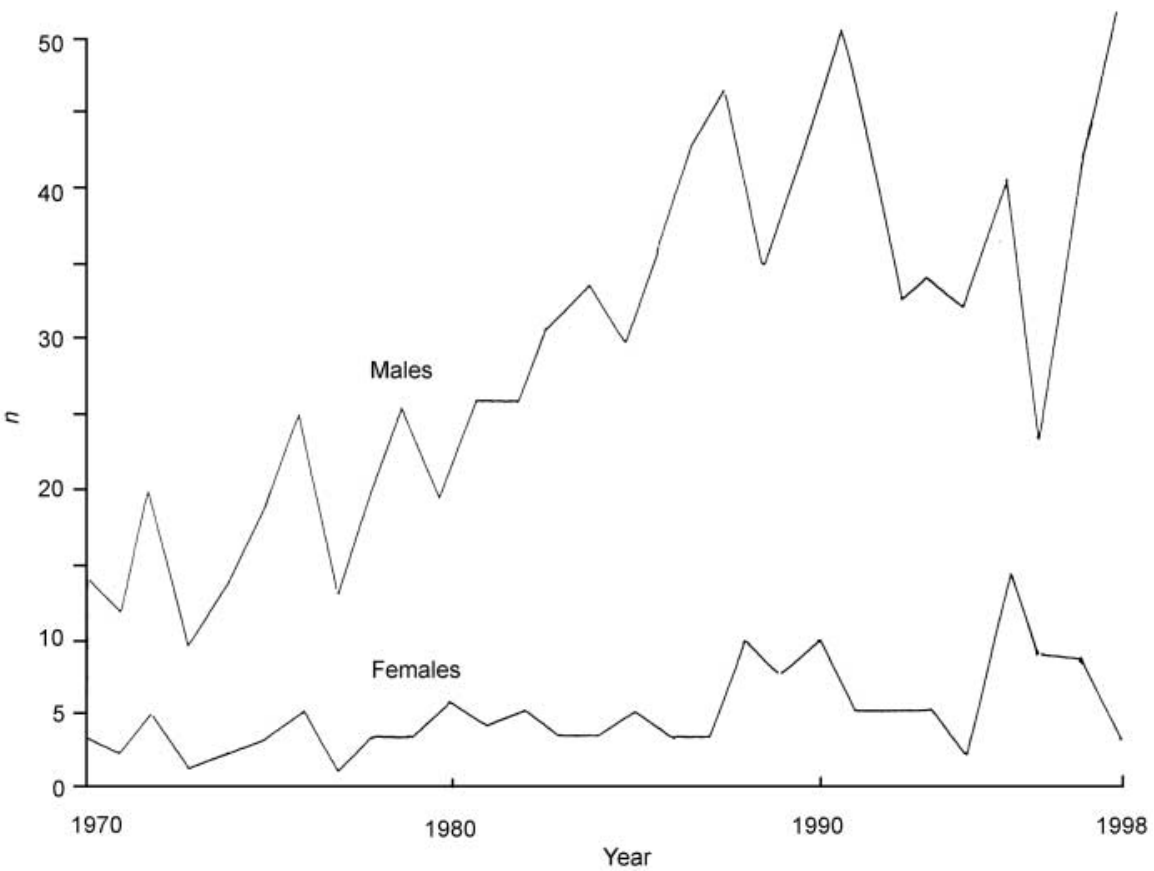

Fig. 4 Suicide by hanging, strangulation and suffocation in the 15-19-year-old age group in England and Wales deaths was principally due to a decrease in drowning.

The summation of suicide, undetermined and accidental rates shows a decrease for males between 1970-1998 and little change for females.

\section{DISCUSSION}

\section{Changes in suicide rate in children and adolescents}

Among children and adolescents, the only group to have shown an increase in official suicide rate since 1970 has been males aged 15-19 years. This increase is still evident when one examines the changes in undetermined and accidental rates during 1970 1998 and indeed the actual increase in suicide may be greater than the official suicide statistics indicate. There has therefore been a clear increase in suicide in 15-19year-old males in England and Wales between 1970 and 1998 and the decline in the mid-1990s reported by Kelly \& Bunting (1998) appears to have been temporary.

For females aged 15-19 years, the official suicide statistics have shown a small decrease between the 1970s and the 1990s. Examination of the undetermined rate for females aged 15-19 years indicates an increase between 1970 and 1998. The increase in undetermined rate between the 1970s and the 1990s may offset the observed decrease in suicide rate. This is also true of the summated rates for undetermined and accidental deaths by methods similar to suicide. It is therefore possible that there was a small increase in suicide in females aged 15-19 years between the 1970s and the 1990s, although at a much lower level than in males.

There has been no change in official suicide rate for males aged 10-14 years between the 1970s and the 1990s, with a slight decrease in suicide rate for females of this age during the same period. For males and females aged 10-14 years, the increase in undetermined deaths may indicate small increases in misclassified suicide which are not evident in the recorded suicide statistics. The decline in accidents by methods similar to suicide for males and females aged 10-14 years, however, acts counter to the increase in undetermined death. It is likely, therefore, that there has been little change in the actual rate of suicide in 10-14-year-olds between the 1970s and the 1990s. 
Table 2 Suicide, undetermined death and accidental death by methods similar to suicide in 10-14-year-olds in England and Wales

\begin{tabular}{|c|c|c|c|c|c|c|}
\hline & \multicolumn{2}{|c|}{$1970-79$} & \multicolumn{2}{|c|}{$1980-89$} & \multicolumn{2}{|c|}{$1990-98$} \\
\hline & $n$ & (Rate') & $n$ & (Rate') & $n$ & (Rate') \\
\hline \multicolumn{7}{|l|}{ Suicide } \\
\hline Male & 29 & (I.4) & 25 & (1.5) & 22 & (1.4) \\
\hline Female & 24 & (1.2) & 17 & $(1.0)$ & 14 & (0.9) \\
\hline \multicolumn{7}{|c|}{ Undetermined } \\
\hline Male & 75 & (3.8) & 101 & $(5.7)$ & 91 & (5.6) \\
\hline Female & 29 & (I.5) & 35 & (2.1) & 47 & (3.0) \\
\hline \multicolumn{7}{|l|}{ Accidental } \\
\hline Male & 552 & $(27.7)$ & 401 & $(23.2)$ & 182 & (II.I) \\
\hline Female & 93 & (4.9) & 81 & $(4.8)$ & 52 & (3.4) \\
\hline \multicolumn{7}{|c|}{ Suicide and undetermined } \\
\hline Male & 104 & $(5.2)$ & 126 & $(7.2)$ & 113 & (7.0) \\
\hline Female & 54 & (2.7) & 52 & (3.I) & 61 & (3.9) \\
\hline \multicolumn{7}{|c|}{ Suicide and undetermined and accidental } \\
\hline Male & 656 & (32.9) & 527 & $(30.4)$ & 295 & $(18.1)$ \\
\hline Female & 147 & $(7.6)$ & 133 & (7.9) & 113 & (7.3) \\
\hline
\end{tabular}

I. Rate per million population aged $10-14$ years.

\section{Changes in method of suicide}

Since the 1970s we have observed substantial changes using different methods of suicide. Suicide by self-poisoning with solids and liquids (overdosing) peaked in the 1970 s and has subsequently decreased for both males and females aged 10-19 years. For males in the 15-19-years group, the observed increase in suicide during the 1980s was due to an increase in hanging, strangulation and suffocation, and poisoning with motor vehicle gas. Since poisoning with motor vehicle exhaust gas decreased in the mid-1990s, there was a temporary decrease in the male suicide rate, followed by a further increase associated with higher numbers of hangings, which has persisted up to 1998. Changes in self-poisoning with motor vehicle exhaust gas and hanging were less evident in females aged 15-19 years and in males and females aged 10-14 years. These three phases can be described as epidemics of suicide, first by overdosing, then by poisoning with vehicle exhaust gas and currently by hanging, the latter two principally affecting older male adolescents.

\section{Reasons for the increase in suicide in males aged 15-19 years}

It should be noted that the high suicide rate in older male adolescents blends into the general phenomenon of higher suicide rates in young male adults (McClure, 2000a). As male adolescents move into adulthood their risk of suicide increases further (Kelly \&
Bunting, 1998). Consideration of causal mechanisms is speculative, although it is informed by the results presented and may lead to future research which will test hypothetical causal mechanisms.

Suicide is the consequence of a highly complex interaction of factors affecting the young person in their ecological environment (McClure, 2000b,c). Consideration must be given to factors which may make older male teenagers more vulnerable than female teenagers and younger males. The 10-14-year-old group are presumably shielded by adults from exposure to factors which may affect older teenagers. They may also be less likely to have the cognitive and practical ability to plan and carry out a suicidal act. Although older female teenagers (aged 15-19 years) are subject to social pressures, as is evident from high rates of depression and eating disorder, they may be subject to different pressures compared with older male teenagers. Similarly, their response to these pressures may differ and there may be different coping strategies adopted by females. Female teenagers who deliberately harm themselves are less likely to use highly lethal methods. We must consider factors which may be associated with suicidal behaviour which have worsened in recent years, particularly for older male teenagers. Additionally, psychological autopsy studies using coroners' records to trace contacts of the deceased person may shed light on the reasons for committing suicide (Appleby et al, 1999).
It is important to examine not only the records of individuals given a verdict of suicide but also undetermined or accidental deaths by causes similar to suicide.

\section{Factors associated with suicide in the young}

\section{Psychiatric disorder}

Psychiatric disorder in the young is associated with increased risk of suicide, with comorbid disorder indicating especially high risk (Shaffer et al, 1996). Suicidality has a strong and independent association with symptoms of depression (Fombonne, 1998). Although rates of psychiatric disorders have increased during the past 20 years, change in the rate of depression does not account for the recent increase in young male suicide (Fombonne, 1998). In a psychological autopsy study of young suicides Appleby et al (1999) found that major mental illness and personality disorder were common. In a meta-analysis by Harris \& Barraclough (1998) an increased risk of suicide in child and adolescent psychiatric patients was found. Shaffer et al (1996) demonstrated that past suicidal behaviour was a strong risk factor for subsequent suicide. Multiple acts of deliberate selfharm increase the risk of suicide (Hawton et al, 1998).

\section{Substance misuse}

Suicidality has a strong and independent association with substance misuse, particularly with alcohol, which is the most frequently misused substance (Fombonne, 1998). Substance misuse predates suicidal behaviours in most individuals, suggesting that substance misuse leads to subsequent suicidality. Furthermore, Fombonne (1998), suggests that alcohol misuse is the mechanism involved in the recent increase in male suicide. Prevalence rates of alcohol use increase throughout adolescence, with heavy drinking being a problem particularly for males. It should be noted that the increase in suicide rates in young men up to the 1990s occurred during a period of greater use of alcohol and drugs among young people. In a psychological autopsy study, Appleby et al (1999) confirmed that young people committing suicide were more likely to have misused alcohol or drugs. Alcohol also makes a contribution to the suicidal acts of some individuals, excessive blood alcohol levels being found at post-mortem in over one-fifth of cases 
(Hawton et al, 1999). Substance misuse is one of the strongest predictors of suicide following non-fatal self-harm in young people (Hawton et al, 1999).

\section{Disrupted relationships}

Shaffer et al (1996) demonstrated a higher incidence of disrupted family background. The recent increase in family breakup, often with the loss of the father to the family, may have affected boys to a greater extent than girls. In Appleby et al's (1999) psychological autopsy study of young people, those committing suicide were more likely to have disturbed relationships and recent adverse life events. Abuse, which is related to family dysfunction, has been increasingly reported for both genders, but it may have affected young males more in relation to completed suicide. Similarly, reports of increasing bullying may have affected young males more than females. Older teenage boys are more likely to be out of their parents' control, particularly in single parent families, and it is possible that this might lead them into problems which would produce a suicidal reaction. In Fombonne's (1998) sample of referred male adolescents, however, a history of family breakdown was not specifically associated with suicidal behaviour.

\section{Social exclusion}

Appleby et al (1999) found increased rates of unemployment in young suicides. It should be noted, however, that there has been an improvement in the economy and unemployment statistics since the early 1990s (Office for National Statistics, 1999), although the suicide rate for male adolescents remains high. Gunnell et al (1999b) demonstrated significant associations between unemployment and suicide among younger men and women. Hawton et al $(1998,1999)$ demonstrated an association of suicide with unemployment and lower social class in the population of very young suicides. Social problems, homelessness, arrest and involvement in the judicial process may be further stresses for young males.

\section{Male gender role}

The gender difference in rates of suicide is remarkable (Gunnell et al, 1999a). The changing role of men and women in modern society may affect their propensity to commit suicide. Although some stresses are common to both genders the change in the role of young women may have enhanced their self-esteem and thus given them relative protection in relation to suicide. Young women may also have better coping strategies such as the use of supportive social networks. Conversely, new roles and expectations of young men in society may lead to loss of self-esteem if they are unable to live up to expectations. They may then be vulnerable to suicide if they lack appropriate supportive social networks or are unable to communicate their concerns.

\section{Method availability}

During the 1980s and early 1990s increased suicidal risk may in part have been due to the availability of a highly lethal agent vehicle exhaust gas - which was favoured by young males as a method of suicide. Since the mid-1990s, however, the use of this method has declined, in part due to the introduction of catalytic converters (McClure, 2000a). The fact that suicide in males has remained high, due to an increase in hanging, indicates that the increase was not entirely due to availability of a new method, but was probably also related to increased psychosocial stress. Reasons for the increase being principally for males in the 15-19-years age band among the younger population need to be considered. During the 1980s and early 1990s other groups may have been protected by having less access to, and familiarity with, motor vehicles. Similarly, hanging may be more impracticable for younger age groups and less acceptable to older teenage females. Hawton et al (1999) showed that the majority of lethal overdoses were with a small number of substances, in particular co-proxamol (paracetamol and dextropropoxyphene).

\section{Prevention}

When considering prevention, the individual should be seen in an ecological interactive relationship with the environment, where the suicidal act may be a response to internal and external stresses (McClure, 2000b). All of the above factors should be considered when planning a preventive strategy.

Restricting the availability of dangerous substances (such as co-proxamol) should be considered. Additionally, reduction of drug and alcohol misuse by young people may help to prevent suicide. Health education and the provision of suitable services should be targeted at young people with other risk factors, such as social exclusion or unemployment, or those who carry out non-fatal self-harm. Suicide among the young may be precipitated by interpersonal problems, indicating that improvements in interpersonal and life skills may be beneficial (Hawton et al, 1999). Furthermore, young people should have the knowledge of where to obtain help, in times of crisis.

A substantial proportion of young people who commit suicide who have engaged in previous self-harm have neither been referred to a general hospital nor seen their general practitioner (Hawton et al, 1999). Hawton suggests that the significance of the self-harm, as well as the expression of suicidal ideation, needs emphasising in public education so that more individuals at risk can receive attention from clinical and other support agencies. It is important that reporting and portrayal of suicide should be modified so that it is not glamorised and does not encourage young people to commit suicide.

Although evidence for the efficacy of treatment following deliberate self-harm is currently not strong (Hawton et al, 1998), the fact that parasuicide is an important predictor of possible future suicide means that efforts should be made to identify and treat those at highest risk. Half of Hawton et al's (1999) sample had seen a general practitioner within 3 months of death and one-third within a month. Nearly onethird of the sample had been in psychiatric care in the year before death. Prevention of suicide in the young therefore involves improvements in general practice and adolescent psychiatric services, in addition to general public health measures.

\section{ACKNOWLEDGEMENT}

I thank the Office for National Statistics for their support.

\section{REFERENCES}

Appleby, L., Cooper, J., Amos, T., et al (1999)

Psychological autopsy study of suicides by people aged under 35. British Journal of Psychiatry, 175, 168-174.

Fombonne, E. (1998) Suicidal behaviours in vulnerable adolescents. Time trends and their correlates. British Journal of Psychiatry, 173, 154-159.

Gunnell, D., Wehner, H. \& Frankel, S. (1999a) Sex differences in suicide trends in England and Wales. Lancet, 353, 556-557.

_ , Lopatatzidis, A., Dorling, D., et al (1999b)

Suicide and unemployment in young people. Analysis of 
trends in England and Wales, 1921-1995. British Journal of Psychiatry, 175, 263-270.

Harris, E. C. \& Barraclough, B. (1998) Excess mortality of mental disorder. British Journal of Psychiatry, 173, II-53.

Hawton, K., Arensman, E., Townsend, E., et al (1998) Deliberate self harm: systematic review of efficacy of psychosocial and pharmacological treatments in preventing repetition. British Medical Journal, 317 $44 I-447$

—, Houston, K. \& Shepperd, R. (1999) Suicide in young people. Study of 174 cases, aged under 25 years, based on coroners' and medical records. British Journal of Psychiatry, I75, 27I-276.

Kelly, S. \& Bunting, J. (1998) Trends in suicide in England and Wales, 1982-1996. Population Trends, 92. 29-4l.

Madge, N. \& Harvey, J. (1999) Suicide among the young - the size of the problem. Journal of Adolescence, 22, $145-155$.

McClure, G. M. (1984a) Recent trends in suicide amongst the young. British Journal of Psychiatry, 144 134-138.

- (1984b) Trends in suicide rate for England and Wales, 1975-80. British Journal of Psychiatry, I44, 119-126.

- (1986) Recent changes in suicide among adolescent in England and Wales. Journal of Adolescence, 9, 135-143.

— (1987) Suicide in England and Wales, 1975-1984. British Journal of Psychiatry, I50, 309-314.

- (1988) Suicide in children in England and Wales. Journal of Child Psychology and Psychiatry, 29, 245-349.

- (1994) Suicide in children and adolescents in England and Wales, 1960-1990. British Journal of Psychiatry, 165, 510-514.

- (2000a) Changes in suicide in England and Wales, 1960-1997. British Journal of Psychiatry, 176 64-67.

\section{CLINICAL IMPLICATIONS}

- Males aged 15-19 years are a high risk group for suicide among the young.

- Increasing deaths by hanging now make it the most common cause of suicide in the young.

- The four-fold increase in undetermined deaths in males and females aged 15-19 years since the 1970s may indicate concealed suicides.

\section{LIMITATIONS}

There is possible mis-classification between suicide, undetermined and accidental death categories.

- The study design does not explain the mechanisms behind changes in suicide rate.

- Causal explanations are multifactorial and complex due to the incompletely understood psychosocial ecology of young people.

G. M. G. MCCLURE, FRCPsych, Brent, Kensington, Chelsea \& Westminster Mental Health NHS Trust and Imperial College School of Medicine, Child and Adolescent Services, Chelsea and Westminster Hospital, 369 Fulham Road, London SWI0 9NH

(First received 23 May 2000, final revision 19 October 2000, accepted 27 October 2000)

- (2000b) An integrative ecology. In Family Matters: Interfaces between Child and Adult Mental Health (eds P. Reder, M. McClure \& T. Jolly). London: Routledge.

- (2000c) Adolescence. In Family Matters: Interfaces between Child and Adult Mental Health (eds P. Reder, M. McClure \& T. Jolly). London: Routledge.

\section{Office for National Statistics (1991-1998) Mortality} Statistics: Cause. London: HMSO

— (1999) Social Trends. London: Stationery Office.
Office of Population Censuses and Surveys (1974-1990) Mortality Statistics: Cause. London: HMSO.

Registrar General's Office (1960-1973) Registrar General's Statistical Review for England and Wales. Part I: Tables (Medical). London: HMSO.

Shaffer, D., Gould, M. S., Fisher, P., et al (1996)

Psychiatric diagnosis in child and adolescent suicide. Archives of General Psychiatry, 53, 339-348. 